\title{
Objectivity, Proximity and Adaptability in Corporate Governance
}

\author{
By: Arnoud W.A. Boot and Jonathan R. Macey \\ Working Paper Number 266 \\ September 1999
}


Revised, 8 September 1999

\title{
Objectivity, Proximity and Adaptability in Corporate Governance
}

by

\author{
Arnoud W.A. Boot ${ }^{*}$ and Jonathan R. Macey ${ }^{* *}$
}

"University of Amsterdam, Faculty of Economics and Econometrics, Roetersstraat 11,

1018 WB, Amsterdam, The Netherlands, e-mail: awaboot@fee.uva.nl

** Cornell University School of Law, 306 Myron Taylor Hall, Ithaca, NY 14853-4901, U.S.A,

e-mail: macey@law.mail.cornell.edu

Acknowledgements: The authors acknowledge the support through the Sloan Project on Corporate Governance at Columbia Law School. Arnoud Boot also acknowledges his stay as Olin Fellow at Cornell University. We thank Mark Roe, Eric Talley and seminar participants at Columbia, Michigan (Davidson Institute), Yale and Amsterdam for their comments. The usual disclaimer applies. 


\title{
OBJECTIVITY, PROXIMITY AND ADAPTABILITY IN CORPORATE GOVERNANCE
}

\begin{abstract}
Countries appear to differ considerably in the basic orientations of their corporate governance structures. We postulate the trade-off between objectivity and proximity as fundamental to the corporate governance debate. We stress the value of objectivity that comes with distance (e.g. the market oriented U.S. system), and the value of better information that comes with proximity (e.g. the more intrusive Continental European model). Our key result is that the optimal distance between management and monitor (board or shareholders) has a bang-bang solution: either one should capitalize on the better information that comes with proximity or one should seek to benefit optimally from the objectivity that comes with distance. We argue that this result points at an important link between the optimal corporate governance arrangement and industry structure. In this context, we also discuss the ways in which investors have "contracted around" the flaws in their own corporate governance systems, pointing at the adaptability of different arrangements.
\end{abstract}

Key words: corporate governance, comperative systems, corporate finance, economic reform, convergence. 


\section{OBJECTIVITY, PROXIMITY AND ADAPTABILITY IN CORPORATE GOVERNANCE}

\section{Introduction}

In advanced market economies, one observes significant diversity in the ways that alternative corporate governance systems confront the basic problem of corporate governance, which we take to be providing reasonably credible assurances to suppliers of capital that they will receive a return on their investment ${ }^{1}$. Yet these differences do not appear to affect overall productivity or capital formation at least in ways that are capable of detection. It is this basic insight that motivates this paper, which, at its core, is about the adaptability of corporate governance systems.

Alternative corporate governance systems establish initial sets of legal entitlements among claimants to firms' cash flows, specifying different levels of protection for different types of investors. A cursory look at the corporate balance sheet reveals that, one way to evaluate a corporate governance system is on the basis of how well it protects fixed claimants versus equity claimants. Those systems that provide protections for both sorts of claimants should, presumably, function the best, since their capital structure will be the least distorted by the flaws in their corporate governance systems. The U.S. system of corporate governance has been singled out for acclaim because of the strong protections it affords to small-stakes equity claimants. The German system has been identified as

\footnotetext{
${ }^{1}$ Shleifer and Vishny (1997) characterize the corporate governance problem as dealing with the ways that suppliers of finance seek to assure themselves of a return on their investments.
} 
providing particularly strong protections for fixed claimants. By contrast, corporate governance systems such as Italy's or Russia's, may not protect either fixed or equity claimants. Firms in these countries may then be cut off from important sources of capital and must resort to primitive corporate governance devices (such as family control) in order to obtain capital.

In general, however, all corporate governance systems seek to address the agency problems that plague the separation of ownership and control. One potential interpretation of the alternative corporate governance arrangements that we observe is that they reflect the ways in which investors have "contracted around" the flaws in their own corporate governance systems in order to make the most efficient investments possible, given the constraints imposed by the extant corporate governance system. This points at the adaptability of corporate governance arrangements ${ }^{2}$.

The most commonly invoked paradigms of corporate governance are the U.S. system of corporate governance which boasts strong capital markets but possibly weak institutional constraints on management, and the German model, where strong institutional (bank) controls on management may compensate for weak capital markets. This trade-off between institutional and market controls has received a considerable research interest. Coffee (1991) and Bhide (1993) have identified a trade-off in corporate governance between the characteristic of liquidity, which provides investors with a ready exit option in case their investment goes sour, and the characteristic of voice, which gives investors

\footnotetext{
${ }^{2}$ An important illustration of the potential powerful incentives toward adaptability is the degree in which incentive compensation contracts are present. Incentive contracts like stock options and other pay-for-performance remuneration schemes are (most) needed whenever lack of control and/or observability leave excessive discretion to managers. How could managers be induced to use their discretion in the interest of shareholders, or potentially more general, in the interest of the firm rather than (only) serving their self-interest? Here pay-for-performance remuneration schemes might be valuable. We can envision some differences in discretion across corporate governance systems; e.g. a market-oriented corporate governance system with diffused share-ownership may leave more discretion to management and thus necessitate incentive compensation contracting. In this sense, systems are "adaptable" and differences in the prevalence of incentive compensation
} 
the ability to affect the performance of the firms in which they have invested if they become dissatisfied. The latter is reminiscent of institutional controls, the former points at the role of capital markets. It appears that investors who wish to acquire more voice in the running of their firms must, at least to some extent, sacrifice their exit option by giving up liquidity. Similarly, enhanced liquidity may come at the cost of reduced institutional control.

While these arguments are undoubtedly important, we identify what we regard as a potentially more important tradeoff that must be faced when evaluating a corporate governance system. We envision the tradeoff between objectivity and proximity as central to the corporate governance debate. In systems like those that exist in Germany, the Netherlands and elsewhere, there is often an intimate finely textured involvement in monitoring management either by large shareholders or by autonomous, but possibly entrenched, boards of directors (supervisory boards). It may often be the case that these monitors effectively become insiders and are captured by the firms they are monitoring. Where such capture occurs, the ostensible monitor will tend to adopt the perspective of the firm being supervised. Consequently, the informational advantage enjoyed by the insiders in certain corporate governance systems is mitigated by the fact that these investors may gradually lose the ability to evaluate the performance of the firms they are monitoring in an objective manner.

By contrast, in a corporate governance system like the one that exists in the U.S., less monitoring comes from directors. Instead, the market for corporate control substitutes for direct shareholder involvement. In such a system, considerable distance exists between monitors (investors) and management. Investors may then face an obvious problem in obtaining timely, reliable information. 
This may negatively impact the effectiveness of their governance. In particular, monitoring in the U.S. often is ex post and evaluative rather than ex ante and pro-active. On the positive side, the distance that U.S. investors have from the firms in which they are investing brings with it a degree of objectivity lacking in corporate governance systems where the proximity of monitors subjects them to the risk of capture. A perfect system would combine the benefits of proximity and objectivity. Because this seems unattainable, an optimal corporate governance arrangements would seek to find an optimal middle ground.

This paper is organized as follows. In section 1 we develop a theoretical framework highlighting the source of the corporate governance problem, the objectives of corporate governance and the importance of shareholders in corporate governance. Section 2 develops the point that systems differ in the proximity and objectivity of supervision and control. We develop this formally and show that the optimal distance between management and monitor has a bang-bang solution: either one should capitalize on the better information that comes with proximity or one should seek to benefit optimally from the objectivity that comes with distance. Moreover, we argue that the particular choice of corporate governance arrangement should ideally be tailored to the specific industry structure.

In section 3 we build on our point about adaptability. We discuss the issue of adaptability in the context of the corporate governance arrangements in the U.S. and Italy. The basic point here is Coasean in nature: firms in every country face legal constraints around which they must bargain in order to obtain the corporate governance regimes that meet their own, particularized contracting requirements. We believe that our conclusions about the nature of alternative corporate governance systems are interesting and important because they show the futility of efforts to 
design a perfect corporate governance system. 


\section{Corporate Governance: Theoretical Insights}

\subsection{The corporate governance setting}

On a theoretical level, the problems of corporate governance result from the existence of incomplete contracts. Governance is then desired to resolve the gaps left in these contracts in ways consistent with maximizing the value of the firm. The important contribution addressing this issue comes from Grossman and Hart (1986). They introduce the notion of residual rights of control that stresses the importance of allocating decision power (control) when unspecified contingencies arise. Corporate governance could be defined narrowly as "the set of conditions that shape the ex post bargaining over the quasi-rents generated by a firm" (Zingales (1997)). Under this definition, corporate governance fills in the holes left in incomplete contracts. Corporate governance is irrelevant with complete contracts. These contracts would fully specify the desired course of action, and provided that enforcement and time-inconsistency problems are not an issue (and they are not in a world of complete contracting), no role exists for corporate governance.

The presence of discretion in incomplete contracts makes the allocation of residual rights of control important. The primary focus is now on the accountability of management vis-a-vis stakeholders and the governance and/or supervision provided by those stakeholders. Management -- in this incomplete contracting world -- may have a substantial informational advantage which gives it certain residual rights of control. But who should ideally be granted the residual rights of control? Shareholders lack protection in terms of enforceable contractual rights. They have no legal rights to dividends, capital appreciation or even a return on their initial investments. They also have weak bargaining power because their investment in the firm is sunk once it has been made. This view points at shareholders 
as the prime candidate for being allocated control rights ${ }^{3}$. The question now is how the corporate governance system should be arranged to protect the interests of shareholders.

\subsection{Managerial inefficiencies and shareholder involvement}

The problem of corporate governance is rooted in the separation of ownership and control. When management and shareholders are the same party, control rights are automatically in the hands of shareholders. Many have argued that direct shareholder control over management is therefore desirable. Others, however, have suggested that specific problems arise when shareholders seek to exercise control. Most notably, free-rider problems due to the dispersion of ownership might be insurmountable (Grossman and Hart (1988)). While having large shareholders may overcome this (Shleifer and Vishny (1986)), problems also arise when large shareholders participate in management. Large shareholders may face conflicts of interest that undermine their incentives to maximize firm value. For example, they may enjoy private benefits of control that distort their decision making. Alternatively, large shareholders may themselves be part of organizations that face governance problems (e.g. (public) pension funds, see Romano (1993)).

While these are potentially powerful concerns about the effectiveness of shareholder control, recent research suggests that more fundamental tradeoffs may guide the desired involvement of shareholders in corporate control. Burkhart, Gromb and Panunzi (1997) and Aghion and Tirole (1997) both show that direct shareholder control may discourage new initiatives on the part of managers. A simple

\footnotetext{
${ }^{3}$ Rajan and Zingales (1998) link the choice of residual claimant to the claimants' incentives and abilities to choose the specificity of their contribution to the firm. Highly firm-specific contributions may limit ex post bargaining power. Shareholders, however, could part with their money and thus (partially) distance themselves from the direct decision making, but be granted control rights ex post. The suppliers of other inputs, including workers (labor), are generally not able to distance themselves. That is, they have a more permanent effect on the quality and usage of their input. Granting them control
} 
example would be a situation where project quality depends on both management initiative (effort) and exogenous characteristics of the project. If shareholders are too involved, they may push for a change in projects every time a (marginally) better investment opportunity comes along. Managers would anticipate this possibility and reduce the effort invested in what they perceive as potentially transient projects accordingly. Shareholder involvement may then be counterproductive. A lower level of shareholder involvement may mitigate these perverse incentives ${ }^{4}$.

These observations are consistent with real world corporate governance arrangements, which almost without exception limit direct shareholder involvement. In some cases -- particularly the U.S. -- this is facilitated by relatively dispersed ownership. This limits direct shareholder involvement to at most periodical interference via proxy fights, hostile takeovers or other mechanisms that seek to mobilize shareholders $^{5}$. In the Continental European context more concentrated ownership is dominant. However, this does not readily translate in more shareholder control. In some countries (Germany and southern Europe) cross holdings and pyramid structures shield firms from shareholders. Also, non-executive directors (or supervisory boards in a two tier system) may shield management from

\footnotetext{
rights may then be suboptimal: they would seek to affect or manipulate the firm-specificity of their contributions.

${ }^{4}$ In the Rajan and Zingales (1998) analysis shareholders may push for non-firm specific investments that would optimize their ex post bargaining power at the cost of ex ante efficiency.

${ }^{5}$ In general, shareholder control becomes more powerful when financial difficulties and/or managerial control problems emerge. In those circumstances we often observe concentration of shareholdings.
} 
direct shareholder involvement ${ }^{6}$. This is particularly true in the context of some Continental European countries. In countries like The Netherlands and -- to a lesser extent -- Germany rather autonomous supervisory boards operate semi-independently from shareholders and effectively shield management from direct shareholder involvement. Therefore, as in the U.S., direct shareholder control over management is limited ${ }^{7}$. The main issue, however, is how to facilitate sufficient shareholder control to overcome managerial inefficiencies and address the other objectives of corporate governance.

\subsection{Objectives of corporate governance}

Corporate governance is needed for three reasons. First, and foremost, the necessarily incomplete nature of the corporate contract implies a need for background rules to supply solutions to the unforeseen contingencies that confront investors. More specifically, a corporate governance system should seek to lower contracting costs by providing minority shareholder protection, well defined property rights and default rules and reliable enforcement of such rules. Second, the relationship between investors and managers presents a straightforward agency problem that must be addressed. This relates to the problems inherent in the separation of investment ("ownership") and management ("control"); in particular, measures to overcome potential managerial inefficiencies are needed. Third,

\footnotetext{
${ }^{6} \mathrm{An}$ important issue is the obligation that corporate law imposes on directors. While the system of corporate law is endogenous, and in the end potentially an outcome of the search for an optimal corporate governance arrangement, the specification of the law is still of interest and a determinant of corporate governance practices as well. In this context Shleifer and Vishny (1997) emphasize the fiduciary duty of managers and directors vis-à-vis shareholders. This duty is deeply entrenched in U.S. law. Hamermesh (1997) formulates this as follows: "Delaware law fully supports the proposition, dismissed in some quarters as myopic, that the business and affairs of a Delaware for profit stock corporation are to be managed so as to maximize the value of the investment of one group and one group only, its stockholders". Similarly, U.S. courts have ruled that "A board may have regard for various constituencies in discharging its responsibilities provided there are rationally related benefits accruing to the stockholders" (Revlon, Inc., V. MacAndrews \& Forbes Holdings, Inc. 506 A.2d 619, 624 (Del. 1984)). Blair and Stout (1997) take the controversial point of view that American corporate law should dictate directors to act in the interest of the firm, and not only those of shareholders. This focus mimics Continental European corporate governance arrangements, e.g. Dutch corporate law explicitly states that directors should serve the interests of the firm as an entity.

${ }^{7}$ Shareholder control is very real in cases where no separation exists between ownership and control as may be the case in
} 
the modern corporate enterprise requires a wide variety of firm-specific investments. Thus, an important, though frequently ignored, characteristic of a properly functioning corporate governance system is to protect the firm-specific investments made by those contributing human capital to the firm. By protecting these asset-specific investments, corporate governance systems provide firms and individuals with the necessary incentives to make such investments. ${ }^{8}$

There might be a trade-off between these different objectives of corporate governance. Consequently, improving the performance of a corporate governance system along one vector may weaken the ability of that system to perform along another vector. For example, the weaknesses of the Italian corporate governance system in lacking useful background rules that address the agency problems that exist between investors and managers are well known. However, the strength of the Italian system in nurturing and protecting firm-specific human capital investments is not widely recognized (Macey (1998)).

But how should we go about evaluating corporate governance arrangements? We see two important considerations here. First, many of those corporate governance systems that are characterized as defective somehow appear to produce impressive economic results. Specifically, a number of countries, France, Italy, and by some accounts, even the U.S., which are categorized for various reasons as having deficient corporate governance systems, over time have nevertheless produced superior results in terms of productivity9. How can it be that such "defective" systems are capable of

family businesses. Observe, however, that the corporate governance debate does not focus on these businesses but rather focuses on large(r) public firms characterized by a separation between ownership and control.

${ }^{8}$ We could list separately that a corporate governance system should offer sufficient incentives to innovate, i.e. it should promote entrepreneurial activity.

${ }^{9}$ See Osterland (1997) and Fento (1997) for France, Zingales (1994) and Barca (1995) for Italy, and Jensen (1989-93) and 
generating so much wealth? Why for example does Italy, which appears by all accounts to have a completely dysfunctional corporate governance system, have a higher GDP per capital than Britain, whose corporate governance system appears, on the basis of existing theories to be among the best?

Second, the two paradigmatic governance systems -- the German model and the U.S. model -- are not really models at all. The reality is that these systems are sui generis. The German system is not even a model for the rest of Europe. Nowhere else, for example, exists the "co-determination" of workers and shareholders that is a key characteristic of the German model. Countries such as Italy and France on the one hand (extensive cross holdings and interference by the state), and the Netherlands and Sweden on the other (autonomous boards that may be insufficiently accountable to shareholders), have corporate governance systems that scarcely resemble the German model. Similarly, the U.S. system of corporate governance differs in important ways from the governance systems in place in other common law countries such as Britain and Canada.

In the next section, we develop the tension between proximity and objectivity. Following this, we discuss in section 3 the notion of adaptability of corporate governance arrangements and also illustrate differences in objectivity and proximity across systems.

Porter (1992) for the USA. 


\section{Proximity and Objectivity}

\subsection{Some observations}

We turn now to the trade-off between proximity and objectivity. As we discussed in the introduction, Coffee (1991) and Bhide (1993) suggest a trade-off between liquidity and control. Coffee and Bhide observe that share ownership in the U.S. is very dispersed and may not permit effective discipline of management, but may promote liquidity. The suggested link between dispersed ownership and lack of control has been challenged by both Berglof (1996) and Bolton and Von Thadden (1995)). Berglof argues that a dispersed ownership of shares does not necessarily imply a lack of control. In particular, he states that "the link between liquidity and control is less direct than suggested [...]. Investors and issuers have found a number of ways of keeping control concentrated while increasing liquidity and limiting the capital committed" ${ }^{10,11}$. Bolton and Von Thadden (1995) come with a more subtle argument. A large shareholder might be very desirable, but he may still desire an exit option. Without sufficient liquidity in the market, exit is costly. That is, an investor with a large ownership stake faces a considerable price-impact of his trades. He may then refuse to take a large ownership stake. Liquidity may thus be a pre-condition for having large shareholders. Bolton and Von Thadden's analysis therefore points at a complementarity between liquidity and large shareholders.

Also the empirical observation that shareholders are very dispersed has been challenged. The ownership structure in the U.S. is not as dispersed as is sometimes suggested. While a cross-country comparison indeed shows more dispersion in the U.S. than elsewhere, ownership of shares has

\footnotetext{
${ }^{10}$ Berglof (1996) points at cross holdings and pyramidal ownership structures in particular. These could allow for disproportional voting rights considering the capital committed.
} 
become more concentrated. Much of this comes from the proliferation of pension funds, mutual funds and other institutional investors.

These observations are important and qualify the trade-off between liquidity and control. From our perspective, however, the questions of how control is exercised and what makes control effective are more important. In the U.S., shareholders exercise control via two different channels. One is their impact via the board of directors, the other are interventions via the market for corporate control. As the liquidity/control trade-off suggests, corporate governance systems in the world may differ in the effectiveness of both channels. The Continental European model focuses primarily on the impact of shareholders on managerial decision making via the board of directors, with a marginal role for the market for corporate control. The Anglo-Saxon model differs in that it puts more weight on the market for corporate control and possibly less on the board. We do not want to put too much emphasis on this general characterization of corporate governance arrangements, but want to focus on the fundamental issue concerning the way these systems actually work. Here we identify a primary trade-off between proximity and objectivity in supervision and monitoring. Effective supervision and monitoring is best performed if the monitor (board or shareholders) is both well informed and objective. To see this, observe that monitoring and disciplining management are the primary issues in the corporate governance debate. Such monitoring and discipline may require timely corrective actions. However, the necessary objectivity may require sufficient distance between management and monitor, while being well informed is best accomplished by being close and thus intrusive. This suggests a trade-off between proximity and objectivity.

${ }^{11}$ Another argument could be based on Holmstrom and Tirole (1993). They argue that liquidity may facilitate more effective 
While it is obvious why being well-informed is best accomplished by proximity, it may be less clear why objectivity requires a sufficient distance between management and monitor. Here we draw on research in public choice and psychology to make our point. There is ample evidence in the literature on social psychology to support the view that boards with close proximity to management are likely to become captured by management. For example, the "theory of escalating commitments" predicts that board members will come to identify strongly with management because they have begun a pattern of agreeing with management's decisions. Those earlier decisions, once made and defended, will affect future decisions such that those later decisions will comport with earlier decisions (Myers (1983)). In fact, social psychologists have shown that people tend to internalize their vocational roles. Occupational choices, such as the choice to accept a particular position as a corporate director, will have a strong influence on our attitudes and values (Bachman and O'Malley (1977)). In the context of boards of directors, this means that board members tend to internalize the perspective of management. This causes them to lose objectivity. Observe that this problem does not arise with shareholders in public capital markets who have little or no contact with management.

The basic idea is that once boards of directors have been in place for a while, they are likely to embrace management's perspective. More specifically, after a decision is made and defended by a board, it will affect future decisions such that those decisions will comport with the earlier actions (Rabin (1998)). For example, studies of the decision-making process that contributed to the escalation of the Vietnam War showed that leaders paid more attention to new information that was compatible with their earlier decision. They tended to ignore information that contradicted those earlier assumptions. As one researcher observed, "there was a tendency, when actions were out of line with stock-based executive compensation schemes, and thus improve managerial incentives. 
ideas, for decision-makers to align their actions" (White (1971)). Once ideas and beliefs become ingrained in the mind of a board of directors, the possibility of altering these beliefs decreases substantially. As Tom Gilovich has argued, "beliefs are like possessions", and "when someone challenges our beliefs, it is as if someone criticized our possessions" (Gilovich (1992)).

Economic theory also provides support for the lack of objectivity by boards. From an economic perspective, board supervision tends to make the board jointly responsible with management for the state of the firm. The degree of joint responsibility depends on how much the board has been involved with the firm. The board may abstain from corrective action to preserve its own reputation ${ }^{12}$. This is because taking corrective action may reveal that the board had previously failed to take the proper course of action. Boards may resist action for other reasons as well. They invest considerably in information that is specific to the existing management. Changing management would then potentially dilute the value of this investment. Moreover, to a very large extent, boards of directors can be viewed as legislatures with essentially one interest group constituency: management. Management not only has the time and the resources to cultivate management, it is also the group that presents the board with the information it must have to make its decisions. Over a wide range of issues, all management must do is to present information in a way that is likely to generate support for its perspectives; or in a way that is slightly slanted; or in a selective way, to achieve effective capture of the board. It is, therefore, not surprising that boards often lack objectivity.

\footnotetext{
${ }^{12}$ In this interpretation, the board monitors management. In a two-tier system (e.g. the Netherlands and Germany), this is a clearly defined task for the supervisory board. In the case of a one-tier system (e.g. US and UK) non-executive directors have a role as monitors.
} 


\subsection{A framework: formalization}

We construct a stylistic model to highlight the trade-off in proximity and objectivity that is central to this paper. We identify three parties that determine the corporate governance structure of a firm: management, board and shareholders. Management makes decisions (say decides on a strategy or chooses to invest in a project); board and/or shareholders can monitor and possibly intervene to correct managerial decisions. We will focus on the board as the monitor.

The model has two dates. At $t=0$, management makes a decision. At $t=1$ (immediately following the decision), the monitor can correct a managerial mistake by reversing the decision (e.g. change bad projects to good projects). This initial monitoring is only feasible if the monitor receives timely information. The likelihood of this depends on the distance between board and management. The smaller the distance, the higher is the probability that timely information is received. We let $\beta$ measure the probability that the information is received ${ }^{13}$. Moreover, even when timely information is received, monitoring will not always be successful. Success depends in part on the quality of the monitor. We assume that a monitor is either of intrinsic quality $G$ (good) or $B$ (bad). A good monitor successfully monitors with probability $\alpha_{G}$, and a bad monitor with probability $\alpha_{B}$, with $0<\alpha_{B}<\alpha_{G}<1$. If the monitor fails, managerial failure is not corrected at $t=1$. The monitor can also intervene late, i.e. at $\mathrm{t}=2$. We assume that the monitor is fully informed at that point in time. This allows the monitor to correct an earlier monitoring failure. It can do this regardless of the cause of the monitoring failure; the monitor may either have monitored unsuccessfully or may not have received the timely information. From a firm value maximization point of view, early correction via monitoring is preferred to late intervention. Not correcting managerial failure at all, however, is most costly. We 
assume that late intervention (at $t=2$ ) costs $X$ (relative to successful early monitoring), while abstaining from intervention (in case of managerial failure) costs $\mathrm{Y}$, with $0<\mathrm{X}<\mathrm{Y}$. These costs measure the loss in firm value.

Our assumptions imply that a first best monitoring policy dictates an immediate correction of managerial failure; thus successful early monitoring is preferred. Late intervention is more costly; and abstaining from intervention in case of managerial failure is most costly. Observe that the first best outcome may not be achieved for three reasons. First, the monitor may not obtain timely information on managerial failure and may therefore not be able to correct managerial failure early. Second, the monitor may fail to monitor (again early correction will not materialize). And finally, the monitor may choose to abstain from late intervention. The latter may occur for reputational reasons: late intervention might point at a failure of early monitoring and indirectly signal a lack of monitoring ability.

\subsection{Information structure, remuneration and objectives}

In Figure 1 we have summarized the timing of the correction (monitoring) and intervention decisions ${ }^{14}$.

\footnotetext{
${ }^{13}$ The inverse of $\beta$ could be seen as a measure of the distance between board and management.

${ }^{14} \mathrm{We}$ have analyzed a more expanded version of the model. In that version we have added a publicly observable output signal at $\mathrm{t}=3$. For that more expanded model, all results are qualitatively unaffected. In general, however, adding an output signal introduces some ex post settling up and as such reduces distortions. Details are available upon request.
} 


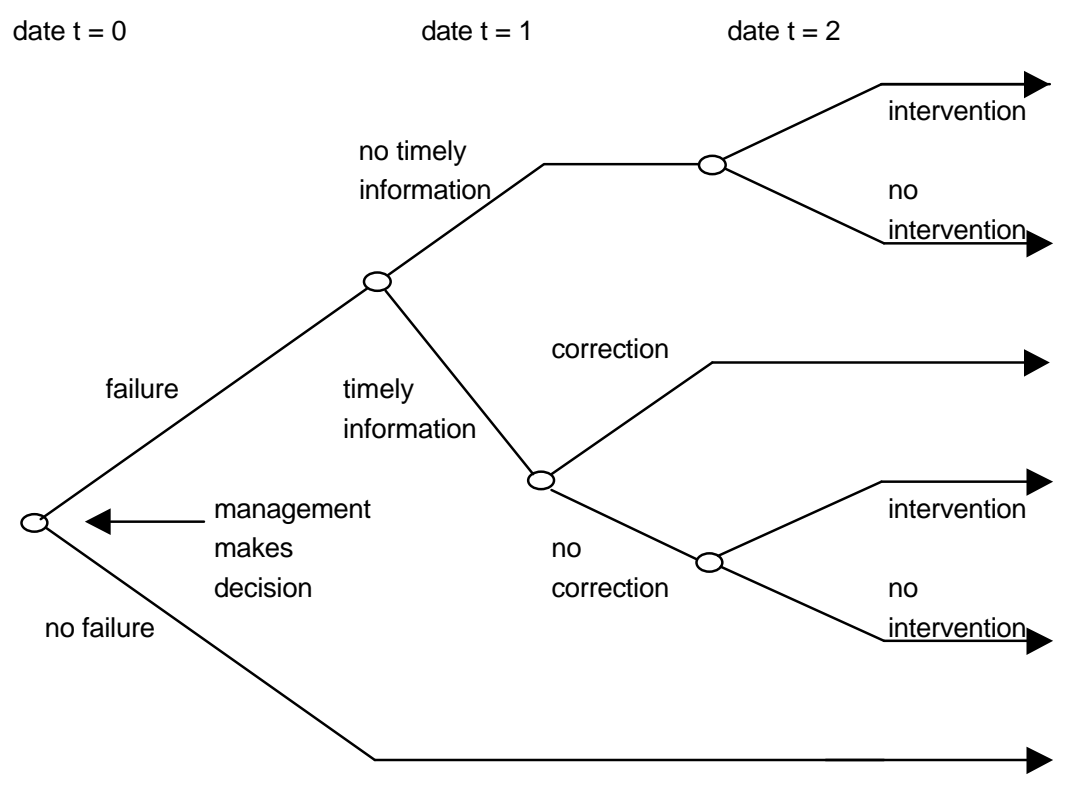

Figure 1 : The timing of correction and intervention decisions

The strategic player in the model is the monitor. The decision process and the incentives of the managers are not considered; the managerial decisions at $\mathrm{t}=0$ are exogenous. The information structure is as follows. Outsiders (including shareholders) only observe the intervention decision of the monitor at $\mathrm{t}=2$. This means that prior to $\mathrm{t}=2$, no information becomes available to outsiders. The intervention or no intervention decision is potentially informative to outsiders because a bad monitor needs to intervene more often than a good monitor. Since outsiders cannot observe actual managerial failure and the success or failure of early monitoring, monitors may choose to distort their intervention decision. Outsiders do know the cross sectional distribution of good and bad monitors. The probability that the monitor is of type $\mathrm{G}$ is $\gamma_{\mathrm{G}}$, and the probability of a type B monitor is $1-\gamma_{\mathrm{G}}$. We will interpret $\gamma_{\mathrm{G}}$ as the initial reputation of the board.

The remuneration of the monitor is linked to his reputation. The monitor seeks to maximize its 
reputation with the intervention or no intervention decision at $t=2$. Let $\mathrm{q}_{\mathrm{t}}$ be the reputation at time

t. The prior is $\mathrm{q}_{0}=\gamma_{\mathrm{G}}$, where $\gamma_{\mathrm{G}}$, as given before, defines the cross sectional distribution of the types of the monitors. Following the intervention (or no intervention) decision at $\mathrm{t}=2$, the prior is updated and the posterior reputation becomes $\mathrm{q}_{2}$. The monitor maximizes ${ }^{15}$

$$
\operatorname{Max} \mathrm{q}_{2}(=\text { reputation or remuneration at } \mathrm{t}=2)
$$

A critical parameter in the model is $\beta$. As defined, $\beta$ measures the probability that the monitor will receive timely information. The core of the analysis is to show how changes in $\beta$ affect the willingness of the monitor to intervene. In Figure 2, we have provided a time line summarizing the main features of the model.

\begin{tabular}{|c|c|c|}
\hline $\mathrm{t}=0$ & $\mathrm{t}=1$ & $\mathrm{t}=2$ \\
\hline+ & + & 1 \\
\hline $\begin{array}{l}\text { - management } \\
\text { chooses project }\end{array}$ & $\begin{array}{l}\text { - monitor does/does } \\
\text { not receive timely } \\
\text { information } \\
\text { (probability } \beta \text { ) } \\
\text { - monitor does/does not } \\
\text { correct managerial failure } \\
\text { (probability } \alpha_{\mathrm{G}} \text { or } \alpha_{\mathrm{B}} \text { ) }\end{array}$ & $\begin{array}{l}\text { - } \text { monitor observes } \\
\text { quality of project } \\
\text { - } \text { monitor does/does } \\
\text { not intervene } \\
\text { - } \text { reputation } \mathrm{q}_{2} \\
\text { established and } \\
\text { remuneration } \\
\text { determined }\end{array}$ \\
\hline
\end{tabular}

Figure 2: Sequence of events

\footnotetext{
${ }^{15}$ In the expanded version of the model that we have analyzed, a noisy output signal is received at $\mathrm{t}=3$. This allows for some ex post settling up, and leads to a further update of the reputation of the monitor. The monitor then maximizes $q_{2}+E\left(q_{3}\right)[1+r]^{-1}$, where $\mathrm{r}$ is the discount rate and $E\left(q_{3}\right)$ is the expected reputation following the output signal at $\mathrm{t}=3$. In that version of the model we could also add a stock price component to the remuneration function. A sufficiently heavy weight on this component may mitigate reputational distortions. But as long as reputational concerns are not fully mitigated, our analysis will remain qualitatively unaffected. Also observe that the reputation-dependent component highly correlates with the stock price component.
} 
We have a signaling game where the monitor chooses an action at $\mathrm{t}=2$ : it either intervenes or does not intervene. The objective is to maximize the function (1). Its choice of action will depend on the publicly known distance between monitor and management (the inverse of $\beta$ ) and on the privately observed quality of the project which may point at an earlier monitoring failure.

\subsection{The analysis}

\section{A Preliminaries}

We first assume that the monitor does not know its own type. In that case, nobody (including the monitor itself) is aware of the quality of the monitor, and only the cross sectional distribution is known. With this assumption, we can show that the monitor does not want to condition its intervention decision at $\mathrm{t}=2$ on the (privately observed) quality of the project, and hence on its potential failure of early monitoring. The intuition is that any form of conditioning on the quality of the project would stigmatize the intervention decision and thus have reputational consequences. Pooling is then preferred. To see this, conjecture an equilibrium where the monitor never chooses to intervene in good projects. Observe that this is an efficient strategy because with intervention firm value would be damaged. But conditional on not intervening in a good project, is the monitor willing to intervene when it discovers a bad project? The answer is no. The reputation of the monitor would suffer because outsiders realize that a bad monitor is more likely to end up in this situation than a good monitor. It would thus lower $\mathrm{q}_{2}$. By not intervening, the downgrade in reputation $\mathrm{q}_{2}$ can be

prevented. Therefore, the monitor chooses not to intervene. This explains why in equilibrium the monitor will not intervene and chooses to pool. But there is one other pooling equilibrium. In that equilibrium, the monitor always intervenes. Obviously, this is an inefficient equilibrium too. But observe that it underscores our general point: if the monitor does not know its own type, it will not 
condition the intervention decision at $\mathrm{t}=2$ on the quality of the project ${ }^{16}$.

There is one exception to these arguments, and that is in the case where $\beta$ equals zero. In that case, everybody knows with certainty that no monitor has received timely information and hence nobody could have monitored successfully. The need to intervene would then not depend on the ability of the monitor, hence reputational considerations are not present. Under these circumstances, an efficient equilibrium exists in which all monitors are willing to intervene when optimal. We summarize these arguments in the following proposition.

Proposition 1: In a setting where monitors do not know their own ability, no monitor is willing to condition its intervention decision on the privately observed quality of the project. Thus, only inefficient pooling equilibriums exist where all monitors intervene either all the time or never. Only in the case where early monitoring could never be effective (i.e. when nobody receives timely information; thus $\beta=0$ ) are monitors willing to intervene efficiently.

We will now focus on the case that monitors are aware of their own type. The market only knows the cross-sectional distribution. Also, we will assume that $\beta>0$, thus the ability of the monitor matters. As we will see, the monitor will now strategically manipulate his intervention decision and interventions are observed in equilibrium. In the next proposition, we first set $\beta$ equal to one. That is, a monitor always has access to timely information.

Proposition 2: In the set of plausible Bayesian perfect Nash equilibria (BNE), good monitors when

\footnotetext{
${ }^{16}$ Throughout we focus on Bayesian perfect Nash equilibria (BNE). Observe that the equilibrium where everybody always intervenes regardless of the type of the project is a BNE if we specify the arbitrary belief that a monitor is bad with
} 
confronted with a bad project intervene with probability $\eta \in[\underline{\eta}, 1]$, while bad monitors intervene with a strictly lower probability $\varepsilon(<\eta)$. In the most efficient BNE, good monitors intervene in bad projects with probability one and bad monitors choose $\varepsilon$ strictly less than one ${ }^{17}$.

The result in Proposition 2 is straightforward. If all good and bad monitors intervene whenever needed, intervention has a severe effect on their reputations $\mathrm{q}_{2}$. That is, in that case more bad than good monitors would have to intervene, hence the pool of monitors that intervenes would include disproportionally many bad monitors. Therefore, an equilibrium may only come about if bad monitors do not always intervene when needed. In other words, bad monitors should follow a mixed strategy.

\section{B Further analysis}

Proposition 2 clearly establishes an inefficiency in corporate governance. The monitor may not want to intervene because it elucidates at an earlier monitoring failure. An interesting issue now is whether efficiency will improve once we increase the distance between monitor and management. At first glance, this seems counter-productive. Increasing the distance will reduce $\beta$, and thus allow more bad projects to escape early correction because timely information did not become available. However, the question is whether this negative volume effect (more bad projects "survive" early monitoring) is offset by a tougher intervention policy ("the behavioral effect"). That is, intervention now stigmatizes less because the lack of timely information makes the ability of the monitor matter less. As a consequence, bad monitors may choose to intervene with a strictly higher probability. The latter effect is good for efficiency. But could it dominate the negative volume effect? These arguments

\footnotetext{
probability one if he does not intervene.

${ }^{17}$ We could also establish two other BNE's: one where nobody intervenes, and one where everybody intervenes. These
} 
suggest a trade-off between proximity and objectivity. Objectivity comes with distance and may improve behavior, while proximity brings more timely information (higher $ß$ ) facilitating early monitoring.

Does there exist an optimal distance between management and monitor? We will focus on the most efficient BNE in Proposition 2 (i.e. only bad monitors manipulate their intervention policy). A first result is stated in Lemma 1.

Lemma 1: Increasing distance (lowering B) strictly improves the intervention policy $\varepsilon$ of the monitor.

The result in Lemma 1 confirms the benefit of objectivity that comes with distance. Intervention, when needed, is more prevalent. However, the result in Lemma 1 does not necessarily point at an increase in efficiency. While the intervention policy $\varepsilon$ improves, more projects escape early correction (monitoring). This is costly; i.e. a cost $\mathrm{X}$ is incurred per project that escapes monitoring. An important question is whether also more projects escape intervention. In other words, can the tougher intervention policy keep up with the extra volume of bad projects? If this would not be the true, then minimizing the distance between monitor and management is always optimal. To see this note that in that case more projects would not be corrected early (leading to a cost X per project) and more projects would escape late intervention (inflating the cost to $\mathrm{Y}$ for those projects). But is it possible that increasing distance will actually reduce the number of projects that escape intervention? This

are clearly inefficient and supported by extreme off-equilibrium path beliefs (i.e., a monitor is bad with probability one if it does not follow the conjectured equilibrium strategy). 
depends on the relative importance of the improvement in $\varepsilon$ vis-à-vis the increase in the number of projects that need intervention. As it turns out, increasing distance always helps reduce the number of projects that escape intervention. We can establish the following result.

Lemma 2: $\quad$ Increasing distance (lowering B) strictly lowers the number of bad projects that escape intervention.

The result in Lemma 2 points at a clear benefit that comes with distance (“objectivity"): the actual number of bad projects that escapes intervention goes down. This shows that, if we focus solely on the number of bad projects that ultimately survives, increasing distance is optimal because the behavioral effect outweighs the volume effect. Does this mean that we should maximize distance? No, this will depend on the relative magnitudes of the costs $\mathrm{X}$ and Y. Following Lemma 2, increasing distance (lowering $ß$ ) reduces the number of bad projects that survive intervention; this saves on the costs Y. However, a lower $\beta$ also implies that fewer projects get corrected early. This elevates the costs X. The optimal distance $\beta$ has a bang-bang solution, as stated in Proposition 3.

Proposition 3: The optimal distance dictates either $\beta=0$ or $\beta=1$. If the cost $Y$ is substantially higher than $\mathrm{X}$ (thus $\mathrm{X}$ is relatively small) then $B=0$ is optimal: objectivity and distance dominate. If $\mathrm{Y}$ is only marginally higher than $X$ then $B=1$ is optimal and the benefits of proximity dominate.

The result in Proposition 3 highlights the importance of the relative magnitudes of $\mathrm{X}$ and $\mathrm{Y}$. It shows that if intervention is important (that is, the difference between $\mathrm{Y}$ and $\mathrm{X}$ is high) monitors should not be close to management, i.e. $\beta=0$. If intervention does not have significant benefits (the difference 
between $\mathrm{Y}$ and $\mathrm{X}$ is small), then proximity together with more early correction, dominate and $\beta=1$.

\section{Interpretation of the results}

The bang-bang type solution raises important questions about the observed differences in corporate governance systems across countries. Can our analysis explain these differences in systems across countries, or does it rather explain differences in corporate governance arrangements between different industries? We believe that it primarily points at the latter: the desirability of differences in governance arrangements between industries. A question that then comes up is for what type of activities or industries either proximity $(\beta=1)$ or objectivity $(\beta=0)$ dominates. As a first observation, for irreversible strategies (or investments) monitoring, and thus early correction, seems crucial. Late intervention would, given the irreversibility, not be particularly valuable, i.e. $\mathrm{Y}$ does not exceed $\mathrm{X}$ by much. This would dictate $\beta=1$. But what determines the irreversibility of investments? An important determinant might be the firm specificity of assets. Opaqueness of assets, which may go hand in hand with irreversibility, requires early correction. Under these conditions, the benefits of proximity are

likely to dominate. Similarly, we could establish for what type of firms objectivity dominates. These would potentially be firms with more liquid and marketable assets. Late intervention would for these firms still be beneficial. The benefits of objectivity that come with distance may then dominate.

We could also relate the notion of irreversibility to intertemporal changes in industry structure. Physical assets (e.g. as in manufacturing) have become less important for the economy at large. This may imply that irreversibility has become less important and suggests that the benefits of objectivity have gained importance. This could have augmented the desirability of market-based corporate governance arrangements. Real world changes in corporate governance arrangements seem consistent 
with this prescription.

While our analysis primarily points at an industry-specific differentiation of corporate governance arrangements, we do realize that corporate governance systems differ primarily between countries. To the extent that laws are needed to fix arrangements, the observed country-specificness of arrangements can be understood. However, our analysis does suggest that a "check the box" option at the chartering stage could be optimal and allow corporations to choose their optimal arrangement. But feasibility is a primary concern. An important question that comes up is whether each type of system depends critically on a prior investment in a certain type of public good that is inconsistent with another system. For example, does the judicial system need to invest in expertise that is specific to a particular system? If this is the case, having diversity in corporate governance systems within a judicial territory might be too costly ${ }^{18}$.

Another issue is whether the adaptability of systems, particularly in adding "bells and whistles" to their basic structures, could mitigate their inherent differences. This points at the issue of adaptability that we will address next.

\section{Adaptability}

\subsection{Role of adaptability}

The analysis and interpretation has so far focused exclusively on a one dimensional interpretation of proximity and objectivity; that is, we let the distance between monitor and management directly 
translate in the monitor's willingness to intervene. No other factors are in play. Obviously this is a simplification. The objectivity of the monitor and the willingness to engage in corrective action is undoubtedly affected by other factors. Here we get to several issues that have become important in the corporate governance debate around the world (see for example the Cadburry Report in England, the Hemple Report in the US and the Vienot Report in France).

These issues can roughly be put in four categories: measures to insure the proper functioning of nonexecutive directors, rights for shareholders, ownership structure issues and, finally, disclosure and transparency requirements. The first group of issues includes the appointment process of (nonexecutive) directors, the remuneration of those directors, the desirability of a two tier board structure (e.g. should the non-executive supervisory board be separated from the CEO/management board?) and the personal liability of directors. The main question underlying this group of issues is whether non-executive directors can be made sufficiently accountable to preserve their independence and thus overcome the problems of proximity. The second group of issues addresses the rights of shareholders. In particular, how can information problems (due to distance) and free-rider problems be resolved to facilitate monitoring and prompt corrective actions by shareholders? In this context, for example, the desirability of proxy-voting and the presence of anti-takeover measures are being discussed. Also the protection of minority shareholders belongs to this group of issues.

The third and fourth groups of issues address the ownership structure and transparency and disclosure. Ownership structure is directly related to the role and effectiveness of shareholders. Are large shareholders needed to facilitate shareholder activism? Are cross holdings helpful? Is a stable

\footnotetext{
${ }^{18}$ We thank Eric Talley for these observations.
} 
core shareholder base desirable? Transparency and disclosure requirements among other things may help to overcome the information gap between (distant) shareholders and management.

At their core, all these issues relate to the adaptability of corporate governance arrangements. These issues might be important considering the bang-bang solution to the optimal governance regime as derived in Proposition 3. In particular, the bang-bang type solution to the optimal structure of corporate governance may go hand in hand with other features that may mitigate the disadvantages of proximity-based and objectivity-based systems. Here adaptability comes in. More specifically, a proximity-based system with for example a finely textured involvement of a board may benefit from shareholder activism. Shareholders could possibly align the board's incentives with their own. The reputational distortions rooted in proximity may then be partially mitigated and the board may choose to intervene more. These observations suggest a potential complementarity between the monitoring provided by boards and the market for corporate control. If the board knows that it will be ousted following a successful disciplinary takeover, the board may become more vigilant to pre-empt the need for corrective takeovers. A takeover threat may then not only discipline management but also discipline the monitoring board.

The importance of adaptability is now easy to see. The issues of ownership structure, shareholders rights and disclosure and transparency may all play a key role in facilitating shareholder activism. These may all help to discipline management and (supervisory) board in both proximity- and objectivity-based systems. Similarly, in both types of systems we see the introduction of measures to facilitate the proper functioning of non-executive (or supervisory) directors. In the context of the Anglo-Saxon one-tier system these measures could be interpreted as an attempt to add some benefits 
of proximity to this objectivity-based system. It illustrates the importance of adaptability.

\subsection{Application to U.S. and Italy}

\section{A Preliminaries}

In this section we show how corporate governance systems can be evaluated on the basis of how well they fill gaps in contingent contracts, resolve agency problems, and promote investments in human capital. This will allow us to focus on the adaptability of those systems. In particular, by understanding the strengths and weaknesses of each system can we understand how these systems adapt to overcome their weaknesses.

Firms that operate within competitive product, labor and capital markets face strong incentives to innovate around any defects that may exist within the framework of any particular set of corporate governance rules. This is the notion of adaptability. In this context we discuss the tradeoff between the value of objectivity that comes with distance, and the value of information that comes with proximity.

The U.S. fits our example of a corporate governance system in which the entities that provide monitoring and discipline may lack information but enjoy objectivity. Italy provides an example of a country with, what appears a defective corporate governance structure. The Italian corporate governance structure permits neither the separation of ownership and control, which brings the "distance" that produces objectivity (e.g. the U.S.), nor the continuous and textured monitoring and discipline by institutions or supervisory boards that provide monitors potentially with real-time information about corporate performance (e.g. Germany and the Netherlands). While it is possible 
to identify corporate governance systems that lack both objectivity and continued and textured monitoring (Italy), it is virtually impossible to identify systems that feature both traits.

\section{B U.S. corporate governance}

The U.S. system of corporate governance gets high marks for its ability to fill in gaps in contingent contracts, mediocre marks for its ability to resolve agency problems, and poor marks for its ability to promote human capital investments. With regard to filling in gaps in contingent contracts, the U.S. system, while far from perfect, does a good job of policing efforts by management to divert corporate assets to their own uses. U.S. law has rules that protect minority shareholders from exploitation, even those who invest in subsidiaries of firms that are part of larger corporate groups ${ }^{19}$. U.S. law also polices rather vigorously against director conflict of interest transactions ${ }^{20}$. More importantly, U.S. directors owe a fiduciary duty of undivided loyalty to their shareholders under basic U.S. corporate governance principles (Scott (1983) $)^{21}$. In addition to these protections for shareholders, a critical element of U.S. corporate law is that most of its provisions are enabling rather than mandatory: investors can customize their own arrangements with the firms in which they have invested in order to tailor these arrangements to correspond to their own particular needs.

While it is true that U.S. law does a good job of dealing with crude efforts by managers to abscond with corporate assets, in recent years the U.S. system has not dealt so well with other, more subtle aspects of the agency problem facing investors in public companies, such as managerial entrenchment in the face of hostile take over bids, or excessive managerial compensation. It is well known that the

\footnotetext{
${ }^{19}$ See Sinclair Oil V. Levien, 280 A.2d 717 (Del. 1971).

${ }^{20}$ See, for example, Subchapter F (sections 8.60-8.63) of the Model Business Corporation Act.

${ }^{21}$ See also footnote 6.
} 
U.S. system of corporate governance is categorized by a degree of separation between ownership and control that is pronounced relative to that in other countries. The U.S. depends more on capital markets and less on banks and large shareholders than other countries (Murray (1997)). As a consequence of this historical phenomenon, which is at least partially attributable to political causes (Roe (1994)), the performance of the American system of corporate governance hinges in part on its ability to resolve agency problems that result from the separation of ownership and management that uniquely characterize the U.S. public corporation.

The way that the U.S. system historically has confronted these problems is through takeovers. A wealth of theoretical arguments and empirical evidence supports the proposition that takeovers address corporate governance problems in general and agency problems in particular by controlling managerial discretion. Shleifer and Vishny (1997) have observed that "takeovers are widely interpreted as the critical corporate governance mechanism in the United States, without which managerial discretion cannot be effectively controlled". Unfortunately, several political developments may have weakened the effectiveness of the market for corporate control. In particular, the collapse of Drexel, Burnham Lambert contributed to the end of the takeover wave of the 1980s by depriving bidders of ready access to the significant capital needed to finance a hostile acquisition. Also, state legislatures and state judiciaries in virtually all important U.S. jurisdictions have succumbed to political pressure to impose legal curbs on the market for corporate control.

These events posed only temporary problems. Takeover entrepreneurs -- and their legal and financial strategists -- are much more dynamic and inventive than many suppose. Following the demise of Drexel, the junk bond market collapsed, but only for a time. Soon, not only were high-yield bonds 
back, but their role in financing takeovers was supplemented by the growth of hedge funds, and by the increased availability of commercial bank financing. The total capital available to finance arbitrage and other takeover related activities is greater today than it was in the 1980s. More importantly, institutional shareholders have become more activist in recent years. They use their political leverage to insure that the balance of power in the market for corporate control does not tip too far in favor of incumbent management (Fisch (1994)). Together with the effective bundling of hostile bids with consent solicitation and proxy fights, hostile takeovers, which had virtually disappeared as a corporate governance device at the start of the 1990s, reappeared around 1995, continue to play an important role in mitigating managerial agency problems ${ }^{22}$.

As noted at the outset, corporate governance systems work to reassure suppliers of capital. Among the more important and illusive sorts of capital is firm-specific human capital. It is here that the vaunted U.S. system of corporate governance reveals its deepest flaws. A distinguishing feature of the U.S. system is its reliance on capital markets. These markets place pressure on corporate managers to deliver profits. A defining attribute of this system is its objectivity. Another distinguishing feature of the U.S. system is its dynamism and flexibility. In particular, participants at

\footnotetext{
${ }^{22}$ Perhaps most significantly, takeover entrepreneurs and arbitrageurs have introduced an innovation, the shareholder rights by-law, that is likely to do even more to invigorate the market for corporate control by eliminating the ability of target company boards of directors to keep their poison pill defensive devices in place once an outside bid has been made. (The new technique is simple. A shareholder proposes an amendment to his firm's bylaws requiring the company's poison pill (and other defensive measures) to expire automatically whenever the firm receives an all cash offer for 100 percent of the firm's stock at a price at least 25 percent above the market. The only way the firm can keep its poison pill is if the shareholders vote to keep the pill within 90 days of receiving the offer.) The Securities and Exchange Commission is requiring firms to include these shareholder rights by-laws in their proxy solicitation materials at their own expense under SEC Rule 14a-8. By refusing to permit companies to exclude shareholder proposals from their proxy solicitations, the SEC has set the stage for a major legal battle. This battle will come when shareholders approve a proposed shareholder rights by-law, and the by-law is then challenged in court by directors claiming that their right to run the company was wrongfully usurped. If Delaware judges refuse to respect the rights of the shareholders by upholding the legality of rights by-laws, institutional investors may start demanding that their firms reincorporate to jurisdictions that provide more rigorous protection for shareholders. However, even if the Delaware judiciary is not persuaded by legal arguments, pressure by institutional investors to find a jurisdiction hospitable to these arrangements may well insure their long-term viability even
} 
all levels of U.S. labor markets are highly mobile. Hiring and firing workers is far easier in the U.S. than in Europe or Japan. These features have been heralded as causing the low rates of unemployment that the U.S. is now enjoying. These advantages are offset, to some extent by costs, which result from the fact that employees, including high-level managers, cannot make credible, long-term commitments to their firms. This reduces the incentives of both firms and managers to make firm-specific investments in these employment relationships. Thus, the unstable nature of their employment relationship has distinct costs as well as distinct benefits.

Another weak aspect of the U.S. corporate governance system is rooted in the fact that U.S. investors are not relational investors: they move in and out of their investor status through arms-length market transactions. As such, in the U.S. investors depend on publicly available information that is inevitably incomplete, crude and backward looking. U.S., investors generally lack the same privileged, detailed information about the firms that they have invested in that institutional investors in other countries may enjoy. U.S. law has attempted to compensate for this deficiency by creating complex and extensive disclosure requirements. While these mandatory disclosure rules may have improved the quality of the information received by investors, they do not change the fact that the information is received only after critical decisions are made. As we have argued in section 2, Continental European systems with large shareholders or direct control by supervisory boards and/or banks allow not only a finer information partitioning and thus more informed monitoring, they also permit investors to participate in decisions before they are made. However, an element of capture may enter that prevents effective governance. Thus both the U.S. and the Continental European models may fail to adequately address more subtle agency problems.

if Delaware's judges are reluctant to enforce them. 


\section{Corporate governance in Italy}

The Italian system of corporate governance is a virtual mirror image of the U.S. system. The Italian system gets low marks for its ability to fill in gaps in contingent contracts, due to its poor legal system and absence of protections for investors' rights. Italian corporate governance also does not perform well in terms of its ability to resolve agency problems, as evidenced by the fact that the duty of loyalty is not an operational concept in Italy for several reasons, not the least of which is that courts have no expertise or inclination to provide protections for non-controlling investors (see Weigmann (1974), Barca (1995), and Macey (1998)). In the Italian corporate governance system two things substitute for the lack of the market-based control systems that characterize U.S. corporate governance. The first is politics. The second is small firms that finance themselves internally.

The state historically has controlled the nation's banks and large companies, and has “constantly made up for failures in the governance environment of private companies by providing them with a steady flow of resources" (Barca (1995), p. 38). The role of the state in corporate governance is hardly salutary. The politicization of capital investment decisions inevitably results in politicized, sub-optimal decisions about capital allocation. In addition to state ownership, the Italian corporate governance system is characterized by complicated cross and pyramidal ownership structures. This system of shareholdings possibly entrenches management, disadvantages minority shareholders, prevents capital market discipline, and stifles the development of a market for corporate control. However, these ownership structures do result in the emergence of a clearly identified, highly stable, controlling coalition. This control group has close ties to management and timely access to whatever information, including confidential corporate information, that it wants. This would allow for a finely textured 
involvement including the ability to make instantaneous changes whenever necessary. The complicated and pyramidal ownership structures do however distort and confuse incentives. Also the proximity of investors to management leads to "joint responsibility" and lack of objectivity that weakens the monitoring role of investors (see section 2). Moreover, legal protection for shareholders in Italy is so poor that external financing is barely feasible for investors who do not receive control rights.

In other words, a flaw in the U.S. corporate governance system is that takeovers are so expensive that it is only cost-effective to address large-scale managerial failures. By contrast, the controlling shareholders who manage the Italian corporate governance system can make changes at a far lower cost, since they already are in control. However, because of their personal involvement in the management of the firm and the complicated ownership structures, these investors are likely to lack the objectivity necessary to make the hard decisions necessary to control agents' behavior.

The success of the Italian economy is due, in large part, to the fact that the country has a disproportionately large number of small firms that perform exceedingly well. An astonishing $98 \%$ of Italian firms have fewer than 20 workers (Macey (1998)). These firms solve corporate governance problems in the simplest way possible: they lack the separation of ownership and management that generates the agency problems that define the corporate governance puzzle in more complex systems. In other words, “corporate governance doesn't matter very much in Italy because there are so few large and medium sized firms" (Macey (1998), p. 29). Complex solutions to corporate governance problems are not necessary in these small firms because individual entrepreneurs and their families in Italy both finance and manage these small family firms, and they have both the incentives and the 
ability to monitor and control shirking.

The rigid, inflexible industrial structure of the Italian corporate governance system also creates strong incentives for managers to make firm-specific human capital investments. This is true in small Italian firms because these firms "are often staffed with family members or close friends of the owner, who can make credible, long-term commitments to employees that, in turn, provide the employees with incentives to make such firm-specific capital investments" (Barca (1995), p. 7).

In other words, the Italian system of corporate governance does not compare favorably with the U.S. system in terms of its ability to protect minority investments, fill in gaps in contingent contracts, or reduce agency costs. Therefore it is not surprising that Italy has weak capital markets and virtually no venture capital. But Italy has flourished because investors and entrepreneurs have innovated around the deficiencies in its corporate governance system by utilizing the closely held corporation. These small, often family-centered businesses have obviated the need for mechanisms that reduce agency cost problems by eliminating the agency relationship. An often overlooked virtue of this system is that it provides strong incentives for managers to make the firm-specific human capital investments necessary to develop specialized skills. Managers in these intimate firms can make these investments secure in the knowledge that they won't be exploited.

\section{Final Observations}

We have postulated the corporate governance problem in developed economies as a trade-off between proximity and objectivity. Both objectivity and proximity have distinct costs and benefits. 
Objectivity goes hand in hand with distance and potentially less information. The latter may reduce the likelihood of timely correction. On the positive side, such a system would facilitate objectivity and reputational concerns would interfere less with necessary interventions. A proximity-based system is more informative and this facilitates timely corrective action. However, reputational concerns may not provide the right incentives for tough intervention decisions. Ideally, corporate governance arrangements should be tailor made to fit the desired governance structure of a particular industry. In some industries the disadvantages of proximity might dominate; in others the lack of information in case of distance and objectivity might be prohibitively costly. Issues of adaptability play a role as well. For example, stronger disclosure requirements may overcome some of the information shortages and facilitate more distance and thus objectivity.

At this stage, we can conclude that observed corporate governance arrangements -- be they intrusive or objective -- do not deal satisfactorily with subtle agency problems, either because of lack of information (the "objective" U.S. system) or capture (the "intrusive" Continental European model). The U.S. model is superior in filling in gaps in contingent contracts thereby lowering contracting costs, but poor in generating high quality information and in protecting human capital and relationship specific investments ${ }^{23}$. The Continental European model provides less satisfactory solutions to contingent contracts, but generates high quality information and is superior in protecting specific human capital investments. The latter holds particularly in a malfunctioning corporate governance system like that of Italy ${ }^{24}$.

\footnotetext{
${ }^{23}$ Observe that the contracting environment in an "objective" type system like the U.S. depends on having enforceable contracts. With proximity, more discretion could possibly be allowed in contracts because the parties to the contracts are "close" and could immediately respond to the gaps in the contract.

${ }^{24}$ Observe that in the case of Italy -- as we discussed -- solutions to the problem of contingent contracts are totally inadequate and also subtle agency problems are addressed poorly.
} 
What can we say about the convergence of corporate governance systems? While we have emphasized the adaptability and resilience of different arrangements, we do believe that systems are converging along some dimensions. In Continental Europe ownership stakes may have been more concentrated. More recently, however, substantial pressure has come about to improve the liquidity of stock markets. The ownership of shares of the general public has grown substantially. This has increased dispersion. In the U.S., we observe more concentration and an increase in institutional investor involvement. Observing the U.S. and Continental European trends, convergence of stock ownership patterns seem underway where concentrated ownership goes hand in hand with dispersed ownership. In other ways, corporate governance systems are also converging. Boards of directors in two-tier systems and non-executive directors have become more and more accountable vis-a-vis shareholders, and are forced to divorce themselves from management. Cozy arrangements between directors and management therefore become less and less acceptable. 


\section{REFERENCES}

Acemoglu, D., 1995, "Corporate Control and Balance of Powers", mimeo.

Aghion, P. and J. Tirole, 1997, "Real and Formal Authority in Organizations", Journal of Political Economy, Vol. 105, p. 473-94.

Bachman, J. and P. O'Malley, 1977, "Self Esteem in Young Men: A Longitudinal Analysis of the Impact of Educational and Occupational Attainment", Journal of Personality and Social Psychology, Vol. 35, p. 365-84.

Barca, F., 1995, “On Corporate Governance in Italy: Issues, Facts and Agency”, Bank of Italy, Rome, manuscript.

Berglof, E., 1996, "Corporate Governance”, in: B. Steil (ed.), The European Equity Markets, London: The Royal Institute of International Affairs, Chapter 5, p. 147-184.

Bhide, A., 1993, "The Hidden Costs of Stock Market Liquidity", Journal of Financial Economics, Vol. 34 (1), p. 31-51.

Blair, M.M. and L. Stout, 1997, “A Theory of Corporation Law as a Response to Contracting Problems in Team Production", Brookings Institution, Working paper.

Bolton, P. and E.L. von Thadden, 1995, "Blocks, Liquidity and Corporate Control”, Working paper.

Burkart, M., D. Gromb and F. Panunzi, 1997, "Large Shareholders, Monitoring, and the Value of the Firm", Quarterly Journal of Economics, Vol. 112, p. 693-728.

Coffee, J.C., 1991, "Liquidity Versus. Control: The Institutional Investor as Corporate Monitor", Columbia Law Review.

Cremer, J., 1995, “Arm's Length Relationships”, Quarterly Journal of Economics, Vol. 110, p. 275-95.

Fanto, J., 1997, "Corporate Governance in American and French Law", mimeo.

Fisch, J.E., 1994, “Relationship Investing: Will it Happen? Will it work?", Ohio State Law Journal, Vol. 55, no. 5, p. 1009-1048.

Fischel, D.R., (1995), Payback, mimeo.

Fritsch, P., 1997, “Pennzoil Holder Proposes Limiting 'Poison Pill' Use”, The Wall Street 
Journal, November 19, B5.

Gilovich, T., 1992, "How We Know What Isn't So: The Fallability of Human Reason in Everyday Life", p. 86.

Grossman, S. and O. Hart, 1986, "The Costs and the Benefits of Ownership: A Theory of Vertical and Lateral Integration”, Journal of Political Economy, Vol. 94, p. 691-719.

Hamermesh, L.A., 1997, "The Shareholder Rights By-Law: Doubts from Delaware”, Corporate Governor Adviser 9, Vol. 5.

Holmstrom, B. and J. Tirole, 1993, "Market Liquidity and Performance Monitoring", Journal of Political Economy, Vol. 101, p. 678-709.

Jensen, M., 1989, "Eclipse of the Public Corporation", Harvard Business Review , Vol. 60, p. 6790.

Jensen, M., 1993, "The Modern Industrial Revolution, Exit, and the Failure of Internal Control Systems", Journal of Finance, Vol. 48, p. 830-881.

Macey, J.R., 1998, “Corporate Governance in Italy: One American's Perspective”, Columbia Business Law Review.

Maug, E., 1997, "Board of Directors and Capital Structure: Alternative Forms of Restructuring", Journal of Corporate Finance, Vol. 3, p. 113-38.

Mayer, C., 1997, "Financial Systems and Corporate Governance: A Review of the International Evidence", University of Oxford, Working paper.

Milbourn, T., 1997, "Comment on Mayer's 'Financial Systems and Corporate Governance", London Business School, Working paper.

Murray, A., 1997, “New Economic Models Fail While America, Inc. Keeps Rolling; Why?", The Wall Street Journal, Monday, December 8, p. A2, col. 1.

Myers, D.G., 1983, Social Psychology, p. 46-47.

Osterland, A., 1997, "France is a Banana Republic: Corporate Governance is Changing in France... Slowly", Financial World, July/August, p. 40-43.

Porter, M., 1992, "Capital Disadvantage: America's Failing Capital Investment System", Harvard Business Review, Sept.-Oct., p. 65-83.

Rabin, M., 1998, "Psychology and Economics", Journal of Economic Literature, Vol. 34, no. 1, p. 11-46. 
Rajan, R. and L. Zingales, 1998, "Power in a Theory of the Firm", Quarterly Journal of Economics, 113 (2), p. 387-432.

Roe, M., 1994, "Strong Managers, Weak Owners, The Political Roots of American Corporate Finance", Princeton University Press.

Romano, R., 1993, "Public Pension Fund Activism in Corporate Governance Reconsidered", Columbia Law Review, p. 795-85.

Scott, K., 1983, "Corporation Law and the American Law Institute Corporate Governance Project”, 35 Stanford Law Review, p. 935-37.

Shleifer, A. and R.W. Vishny, 1986, "Large Shareholders and Corporate Control", Journal of Political Economy, Vol. 94, p. 461-88.

Shleifer, A. and R.W. Vishny, 1997, “A Survey of Corporate Governance”, Journal of Finance, Vol. 52, p. 737-81.

Strausz, R., 1997, "Delegation of Monitoring in a Principal-Agent Relationship", Review of Economic Studies, Vol. 64, p. 337-57.

Warther, V.A., 1994, "Board Effectiveness and Board Dissent: A Model of the Board's Relationship to Management and Shareholders", mimeo.

Weigmann, R., 1974, “Responsibilita' e potere legittimo degli amministratori”, p. 104-13.

White, R., 1971, “Selective Inattention”, Psychology Today, November, p. 47, 82.

Zingales, L., 1994, "The Value of the Voting Right: A Study of the Milan Stock Exchange Experience", Review of Financial Studies, Vol. 7, p. 125-148.

Zingales, L., 1997, "Corporate Governance", forthcoming in The New Palgrave Dictionary of Economics and Law. 


\title{
APPENDIX
}

\section{Proofs for "Objectivity, Proximity and Adaptability in Corporate Governance"}

\author{
by
}

\section{Arnoud W.A. Boot and Jonathan R. Macey}

Definition: Let $\tau \in\{G, B\}$ be the type of the monitor and $\sigma$ the (intervention) strategy at $t=2$, with action $a=a(\sigma) \in\{$ intervene, do not intervene $\}$ and $\sigma \in \psi$ (= the set of strategies). A pair of strategies and market beliefs, $\left[\sigma_{\tau}, \forall \tau ; q_{2}^{a(\sigma)}, \forall \sigma \in \psi\right]$, constitutes a BNE if (i) a monitor of type $\tau$ chooses $\sigma_{\tau}$ optimally according to (1), anticipating the beliefs $q_{2}^{a(\sigma)}$; (ii) $q_{2}^{a(\sigma)}$ translates into remuneration $R_{2}=q_{2}^{a(\sigma)}$ (= response); and (iii) the market belief $q_{2}^{a(\sigma)}$ following an equilibrium move is a Bayesian posterior of $\gamma_{G}$.

Simplification: We will put zero probability weight on the "no failure" branche of the tree in Figure 1. This has no (qualitative) impact on our analysis but considerably simplifies the algebraic complexity of the expressions.

Proof of Proposition 1: In this proposition only does the monitor not know his own type. The strategies therefore will not be conditioned on $\tau$. We first focus on the plausible equilibrium where no monitor chooses to intervene in good projects. For generality, we assume that all monitors potentially follow a mixed strategy and intervene with probability $\kappa$ in the case of a bad project. Observe that intervention implies that a bad project has escaped early monitoring. We now have:

$$
q_{2}(\text { intervention })=\frac{\kappa \gamma_{G} \operatorname{Pr}(\text { monitoring fails } \mid G)}{\kappa \gamma_{G} \operatorname{Pr}(\text { monitoring fails } \mid G)+\kappa\left[1-\gamma_{G}\right] \operatorname{Pr}(\text { monitoring fails } \mid B)}
$$




$$
=\frac{\gamma_{G}\left[1-\alpha_{G}\right]}{\gamma_{G}\left[1-\alpha_{G}\right]+\left[1-\gamma_{G}\right]\left[1-\alpha_{B}\right]}
$$

Observe from (A-1) that the reputational consequences of intervention are independent of $\kappa$. If the monitor decides not to intervene in a bad project, we have:

$$
q_{2}(\text { no intervention })=\frac{\gamma_{G}\left\{\alpha_{G}+[1-\kappa]\left[1-\alpha_{G}\right]\right\}}{\gamma_{G}\left\{\alpha_{G}+[1-\kappa]\left[1-\alpha_{G}\right]\right\}+\left[1-\gamma_{G}\right]\left\{\alpha_{B}+[1-\kappa]\left[1-\alpha_{B}\right]\right\}}
$$

We can now analyze whether a monitor confronted with a bad project will choose to intervene. The monitor evaluates whether

$$
\left.q_{2}(\text { intervention }) \stackrel{>}{<} q_{2} \text { (no intervention }\right)
$$

From (A-1) and (A-2) it follows that for all $\kappa \in(0,1), q_{2}$ (intervention) $<\gamma_{G}<q_{2}$ (no intervention). It now follows immediately that intervention is not optimal, hence $\kappa^{*}=0$. This shows that intervention is suboptimal because it would signal low ability. Similarly, we can prove that a policy of always intervening (thus also in good projects) also constitutes a BNE. See also footnote 16 for the implausible beliefs needed to sustain this equilibrium. This completes the proof.

Proof of Proposition 2: We first show that the conjectured set of equilibria is BNE. Assume 
that no monitor intervenes in a good project, while a proportion $\eta$, respectively, $\varepsilon$ of good and bad monitors with bad projects divest, with $\eta \in[0,1]$ and $\varepsilon \in[0,1]$. The market's updated beliefs follow from Bayes' rule (the superscript $N I$ (or $I$ ) indicates no intervention (or intervention)).

$$
\begin{aligned}
q_{2}^{N I} & =\frac{\gamma_{G} \alpha_{G}+\gamma_{G}[1-\eta]\left[1-\alpha_{G}\right]}{\gamma_{G} \alpha_{G}+\gamma_{G}[1-\eta]\left[1-\alpha_{G}\right]+\left[1-\gamma_{G}\right] \alpha_{B}+\left[1-\gamma_{G}\right][1-\varepsilon]\left[1-\alpha_{B}\right]} \\
q_{2}^{I} & =\frac{\gamma_{G} \eta\left[1-\alpha_{G}\right]}{\gamma_{G} \eta\left[1-\alpha_{G}\right]+\varepsilon\left[1-\gamma_{G}\right]\left[1-\alpha_{B}\right]}
\end{aligned}
$$

A monitor intervenes (or does not intervene) if (see (1))

$$
q_{2}^{I}>(<) q_{2}^{N I}
$$

In the conjectured set of equilibria (A-6) holds as an equality. We first state a useful result.

Result A: $q_{2}^{N I}$ is monotonically increasing (decreasing) in $\varepsilon(\eta) . q_{2}^{I}$ is monotonically decreasing (increasing) in $\varepsilon(\eta)$. For all $\eta \in(0,1]$ and $\varepsilon \in[0,1]$, or $\{\eta=0, \varepsilon>0\}, q_{2}^{I}$ and $q_{2}^{N I}$ are continuous in $\varepsilon$ and $\eta$.

The proof for Result A follows directly from (A-4) and (A-5). We now prove by contradiction that in the conjectured equilibrium $\eta \neq \varepsilon$. Suppose counter factually that $\eta=\varepsilon$. From (A-4) and (A-5) we get $q_{2}^{N I}>q_{2}^{I}$. Then (A-6) shows that no intervention is strictly preferred. This contradicts the optimality of $\eta=\varepsilon$. From Result A, we see that $\varepsilon<\eta$ is necessary for equality in (A-6), and that, $\varepsilon$ is monotonically increasing in $\eta$. We 
show next that for $\eta=1$ and $\varepsilon$ sufficiently small, intervention is strictly preferred. Note that $\left.\lim _{\varepsilon \downarrow 0} q_{2}^{I}\right|_{\eta=1}=1$, whereas $q_{2}^{N I}$ is strictly less than one. Thus, by (A-6), intervention is strictly preferred. Result A establishes $\exists \varepsilon \in(0, \eta)$ for which (A-6) holds as equality.

Now consider a monitor with a good project. At the strategy $\{\varepsilon>0, \eta=1\}$, for the monitor with a bad project for which (A-6) holds as equality, the monitor with a good project is also indifferent between intervening or not. Not intervening is thus a sustainable equilibrium strategy for the monitor with a good project. This shows that the equilibria are Nash. Bayesian Perfect Nash follows since there are no out-of-equilibrium moves. Two other BNE can be identified. These involve either every monitor intervening or every monitor not intervening (see footnote 17 for the implausible beliefs needed to sustain these equilibria).

Proof of Lemma 1: In the most efficient BNE, we have $\eta=1$ and $\varepsilon<1$. We now have for $\beta<1$,

$$
\begin{aligned}
& \hat{q}_{2}^{N I}=\frac{\beta \gamma_{G} \alpha_{G}}{\beta \gamma_{G} \alpha_{G}+\beta\left\{\left[1-\gamma_{G}\right] \alpha_{B}+\left[1-\gamma_{G}\right][1-\varepsilon]\left[1-\alpha_{B}\right]\right\}+[1-\beta]\left\{\left[1-\gamma_{G}\right][1-\varepsilon]\right\}} \\
& \hat{q}_{2}^{I}=\frac{\beta \gamma_{G}\left[1-\alpha_{G}\right]+[1-\beta] \gamma_{G}}{\beta \gamma_{G}\left[1-\alpha_{G}\right]+[1-\beta] \gamma_{G}+\beta \varepsilon\left[1-\gamma_{G}\right]\left[1-\alpha_{B}\right]+[1-\beta] \varepsilon\left[1-\gamma_{G}\right]}
\end{aligned}
$$

We want to show that $\frac{\partial \varepsilon^{*}}{\partial \beta}<0$, thus lowering $\beta$ improves the equilibrium intervention probability $\varepsilon^{*}$. For the equilibrium value $\varepsilon^{*}$ we have,

$$
\left.\hat{q}_{2}^{I}\right|_{\varepsilon=\varepsilon^{*}}=\left.\hat{q}_{2}^{N I}\right|_{\varepsilon=\varepsilon^{*}}
$$


It is easy to show that the LHS of (A-9) is monotonically decreasing in $\beta$, while the RHS is monotonically increasing in $\beta$. Thus intervention stigmatizes less for lower values of $\beta$, and $\frac{\partial \varepsilon^{*}}{\partial \beta}<0$ follows readily.

Proof of Lemma 2: The number of bad projects that escape intervention equals:

$$
K=\left\{[1-\beta]+\beta\left[1-\alpha_{B}\right]\right\}\left[1-\varepsilon^{*}\right]
$$

The first derivative with respect to $\beta$ is

$$
\frac{\partial K}{\partial \beta}=-\alpha_{B}\left[1-\varepsilon^{*}\right]+\left\{[1-\beta]+\beta\left[1-\alpha_{B}\right]\right\}\left\{-\frac{\partial \varepsilon^{*}}{\partial \beta}\right\}
$$

The quantity $\alpha_{B}\left[1-\varepsilon^{*}\right]$ is the "volume effect" and $\left\{[1-\beta]+\beta\left[1-\alpha_{B}\right]\right\}\left\{-\frac{\partial \varepsilon^{*}}{\partial \beta}\right\}$ is the "behavioral effect". We want to show that $\frac{\partial K}{\partial \beta}>0$, that is lowering $\beta$ lowers the number of bad projects that escape intervention.

Observe that $\frac{\partial K}{\partial \beta}>0$ iff

$$
\left\{-\frac{\partial \varepsilon^{*}}{\partial \beta}\right\}>\alpha_{B}\left[1-\varepsilon^{*}\right] \times\left\{[1-\beta]+\beta\left[1-\alpha_{B}\right]\right\}^{-1}
$$


It can be shown - with some tedious algebra - that this condition always holds (hint: get $\varepsilon^{*}$ from (A-9)).

Proof of Proposition 3: Observe from Lemma 2 that minimizing the number of bad projects that escapes intervention dictates $\beta=0$. This saves on the costs Y. But the costs $\mathrm{X}$ will be very high (the lower the $\beta$, the fewer projects get corrected early). The total costs are

$$
\begin{aligned}
& T=\left\{[1-\beta] \gamma_{G}+\beta \gamma_{G}\left[1-\alpha_{G}\right]+[1-\beta]\left[1-\gamma_{G}\right]+\beta\left[1-\gamma_{G}\right]\left[1-\alpha_{B}\right]\right\} X \\
&+\left\{[1-\beta]\left[1-\gamma_{G}\right]+\beta\left[1-\gamma_{G}\right]\left[1-\alpha_{B}\right]\right\}\left[1-\varepsilon^{*}\right][Y-X]
\end{aligned}
$$

We need to compute the derivative $\frac{\partial T}{\partial \beta}$. It is easy to show that for $\mathrm{Y}$ marginally higher than $\mathrm{X}$ (i.e. Y-X is small), $\beta=1$ is optimal, otherwise $\beta=0$ is optimal. 